Canadian

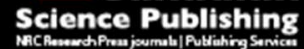

Canadian Journal of Chemistry Revue canadienne de chimie

\title{
Synthesis of zeolite/carbon nanotube composite for gas separation
}

\begin{tabular}{|r|l|}
\hline Journal: & Canadian Journal of Chemistry \\
\hline Manuscript ID & cjc-2016-0305.R1 \\
\hline Manuscript Type: & Article \\
\hline Date Submitted by the Author: & $11-$ Oct-2016 \\
\hline Complete List of Authors: & $\begin{array}{l}\text { Babaei, Majideh; Kerman branch, Islamic Azad University } \\
\text { Anbia, Mansoor; Iran University of Science and Technology } \\
\text { Kazemipour, Maryam; Kerman branch, Islamic Azad University }\end{array}$ \\
\hline Keyword: & Carbon nanotube, Zeolites, Composite, Adsorption, Gas separation \\
\hline & \\
\hline
\end{tabular}

SCHOLARONE ${ }^{m}$

Manuscripts 
${ }^{a}$ Department of Chemistry, Kerman branch, Islamic Azad University, Kerman 7635131167, Iran.

${ }^{b}$ Research Laboratory of Nanoporous Materials, Faculty of Chemistry, Iran University of Science and Technology, Narmak, Tehran 16846-13114, Iran.

*Corresponding author's E-mail: anbia@iust.ac.ir ; Tel: +98 21 77240516; Fax: +98 21 
A hybrid composite of $\mathrm{NaY}$ zeolite and amine modified multi walled carbon nanotube (MWCNT) has been synthesized by hydrothermal method. The obtained NaY/CNT composite (NC composite) was characterized by X-ray diffraction (XRD), Fourier transform infrared (FT-IR), Scanning electron microscopy (SEM) and BET analysis. $\mathrm{CO}_{2}, \mathrm{CH}_{4}$ and $\mathrm{N}_{2}$ adsorption at two different temperatures and $\mathrm{P}<5$ bar on the composite was investigated by the volumetric method. The selectivity of the $\mathrm{NC}$ composite for $\mathrm{CO}_{2} / \mathrm{CH}_{4}$ and $\mathrm{CO}_{2} / \mathrm{N}_{2}$ has been studied and compared with pure $\mathrm{NaY}$ zeolite. Crystal structures of $\mathrm{NC}$ composite were similar to those of pure $\mathrm{NaY}$ zeolite, but the surface area and pore volume of the $\mathrm{NC}$ composite are enhanced. Incorporation of MWCNTs into NaY zeolite increases nucleation sites for the formation of $\mathrm{NaY}$ zeolite crystals, resulting in the smaller size of $\mathrm{NaY}$ zeolite crystals. Gas adsorption capacity and selectivity of NC composite increased because of enhancement of micropore volume. The results confirm that $\mathrm{NC}$ composite is a promising material for the separation and purification of gases. 
48

49

50

51

52

53

\section{Introduction}

Carbon dioxide is the main greenhouse gas that released to the environment as a result of fossil fuel combustion. Currently, natural gas is used as an environmentally friendly fuel compared with other hydrocarbon fuels. In year 2010, natural gas has provided $23.8 \%$ of world total energy consumption and it is predicted to grow by $50 \%$ up to $2040 .^{1}$

Natural gas is composed mainly of methane (80-95\%), but can also contain varying amounts of undesirable components such as heavier hydrocarbons, carbon dioxide, nitrogen and $\mathrm{H}_{2} \mathrm{~S}$. For prevention of equipment and pipeline corrosion, the $\mathrm{CO}_{2}$ and $\mathrm{N}_{2}$ concentrations must not exceed $2 \%$ and $4 \%$, respectively. ${ }^{2}$ Therefore, removal of $\mathrm{CO}_{2}$ from $\mathrm{CO}_{2} / \mathrm{CH}_{4}$ mixture is very important in chemical and petrochemical industries. Moreover, the separation of $\mathrm{CO}_{2}$ from $\mathrm{N}_{2}$ in the flue gas (post-combustion) and also the removal of $\mathrm{CO}_{2}$ from hydrogen (pre-combustion $\mathrm{H}_{2} / \mathrm{CO}_{2}$ ), reduces the emission of $\mathrm{CO}_{2}$ in the atmosphere.

Utilization of adsorption based methods in separation and purification of various gas mixtures is promising for reduction of $\mathrm{CO}_{2}$ emission. Diverse porous materials, such as porous carbon, ${ }^{3,4}$ activated alumina, ${ }^{5,6}$ metal organic frameworks (MOFs) ${ }^{7,8}$ and zeolites ${ }^{2,9}$ have been utilized for this purpose. Among adsorbents, zeolites due to their high adsorption capacity and selective $\mathrm{CO}_{2}$ adsorption are appropriate adsorbents for $\mathrm{CO}_{2}$ adsorption and separation. Moreover zeolites are cost-effective and have high hydrothermal stability. So far zeolites have been widely utilized as adsorbents for separation of different gas mixtures. ${ }^{10-17}$

The adsorption capacity of zeolites, surface area and pore volume can be increased by their modification. Common modifications of zeolites for improvement of adsorption capacity are incorporation of amine groups into their structure ${ }^{18-20}$ and employing different metal ions. ${ }^{21,22} \mathrm{~A}$ few articles about the synthesis of the carbon/zeolite composite materials have been reported with enhanced porosity and adsorption capacity. ${ }^{23-30}$ Some works have been reported on incorporation of CNTs into MOFs and their effect on adsorption performance. ${ }^{31-36}$ However, there are no reports about the incorporation of CNTs into zeolite structures and their effect on porosity and adsorption capacity of CNT /zeolite composite. Due to low hydrothermal stability of MOF materials at high temperatures and cost-effectiveness of zeolites, in this work, we have synthesized the $\mathrm{NaY} / \mathrm{CNT}$ composite (NC composite) and investigated its efficiency in the improvement of the $\mathrm{CO}_{2}$ adsorption capacity and selectivity of $\mathrm{CO}_{2} / \mathrm{CH}_{4}$ and $\mathrm{CO}_{2} / \mathrm{N}_{2}$. Characterization of these materials was done by X-ray diffraction (XRD), Fourier transform infrared (FT-IR), Brunauer-Emmet-Teller (BET), and scanning electron microscopy (SEM) analysis. Gas adsorption capacity was measured by volumetric method and also effect of rising temperature on adsorption capacity and selectivity of the composite has been studied. 


\section{$78 \quad$ Experimental}

\section{Materials}

80 Commercially available MWCNTs, with the purity of around $95 \%$ were supplied by Neutrino Co. in Iran. 81 The inner and external diameter of MWCNTs was in the range of 5-10 nm and 10-20 nm, respectively. The 82 specific surface area of MWCNTs was $>200 \mathrm{~m}^{2} / \mathrm{g}$. For pre-treatment of MWCNTs prior to functionalization, 83 Sulfuric acid (95-97\%) and nitric acid (65\%) were used as obtained, without further purification. 384 aminopropyltriethoxysilane (APTES) (purity: $>98 \%$, Merck) was used for the functionalization of MWCNTs 85 with amine groups. The materials utilized to prepare the zeolite were fumed silica $\left(\mathrm{SiO}_{2} 63 \% 200\right.$ mesh, China), sodium aluminate (Merck), sodium hydroxide $(\mathrm{NaOH}>99.999 \%$, Merck), and deionized water. The solvents used in this work were methanol and ethanol obtained from Merck. $\mathrm{CO}_{2}, \mathrm{CH}_{4}$ and $\mathrm{N}_{2}$ gas cylinders with purity $>$ 99.999 were used in adsorption experiments.

$\mathrm{NaY}$ zeolite was synthesized by the following procedure. A reaction mixture with a molar composition of $\mathrm{Al}_{2} \mathrm{O}_{3}: 3 \mathrm{Na}_{2} \mathrm{O}: 5 \mathrm{SiO}_{2}: 200 \mathrm{H}_{2} \mathrm{O}$ was made. To prepare aluminosilicate gel, an aluminum gel (solution 1) and a silicone gel (solution 2) were prepared separately. Solution 1 was prepared by dissolving $2 \mathrm{~g}$ sodium aluminate in $8.79 \mathrm{~g}$ of deionized water. In solution 2, $3.665 \mathrm{~g}$ fumed silica and $1.952 \mathrm{~g}$ sodium hydroxide were dissolved in $33.174 \mathrm{~g}$ of deionized water. Solution 1 was mixed with solution 2 in a polypropylene beaker. The prepared reaction mixture was stirred by a magnetic stirrer at ambient temperature for 3 days, and then the mixture was put into a Teflon-line autoclave and heated at $373 \mathrm{~K}$ in an oven for $12 \mathrm{~h}$. After the performance of hydrothermal crystallization reaction, the $\mathrm{NaY}$ zeolite powders were filtered and dried in an oven.

Before the synthesis of NaY/CNT composite, MWCNTs were pre-treated and functionalized by amine groups. In the way that, first MWCNTs were stirred with a mixture of concentrated $\mathrm{H}_{2} \mathrm{SO}_{4}$ and $\mathrm{HNO}_{3}(3: 1, \mathrm{v} / \mathrm{v})$ at $80{ }^{\circ} \mathrm{C}$ for $6 \mathrm{~h}$, and then filtrated and washed with deionized water for several times, and dried at $50{ }^{\circ} \mathrm{C}$. Then, the carboxylated MWCNTs (MWCNTs-COOH) after dispersing into flasks containing APTES solution

102 (APTES: ethanol of 1:9, v/v) was sonicated for $6 \mathrm{~h}$ and stirred at ambient temperature for $72 \mathrm{~h}$. The mixture was filtered through $0.2 \mu \mathrm{m}$ fiber filters and washed repeatedly with ethanol and deionized water to remove any residual APTES. Then the filtered solid was dried in an oven at $100{ }^{\circ} \mathrm{C}$ for $6 \mathrm{~h}$ and denoted as N-MWCNT. 
The $\mathrm{NC}$ composite was also prepared under the similar hydrothermal procedures of $\mathrm{NaY}$, except various amounts of N-MWCNT were well dispersed in $33.174 \mathrm{~g}$ of deionized water of solution 2 and sonicated for $2 \mathrm{~h}$, and then fumed silica and sodium hydroxide were added. The various amounts of N-MWCNT was used to synthesize $15 \mathrm{wt} \%$ MWCNT incorporated NaY sample. The synthesized NaY/CNT composite is named as NC composite.

\section{Characterization}

The XRD patterns of NaY zeolite and composite were obtained with a powder X-ray diffractometer (Philips PW 1830 X-ray Diffraction) with $\mathrm{Cu}-\mathrm{K} \alpha$ radiation source. The FT-IR experiments were performed by DIGILAB FTS 7000 spectrometer. The sample powders were mixed with $\mathrm{KBr}$ using a mortar and pestle, then pressed into the pellets by a manual pelletizer. The morphologies of the synthesized $\mathrm{NaY}$ zeolite and $\mathrm{NC}$ composite were identified using a KYKY-EM 3200 field emission scanning electron microscope. The porosity properties of the samples were determined by the nitrogen adsorption-desorption isotherms at $77 \mathrm{~K}$ using a micromeritics model ASAP 2010 sorption analyzer. The specific surface area (SSA) was calculated by Brunauer-Emmett-Teller (BET) method.

\section{Gas adsorption measurements}

The $\mathrm{CO}_{2}, \mathrm{CH}_{4}$ and $\mathrm{N}_{2}$ adsorption isotherms at $298 \mathrm{~K}$ were measured by using a laboratory setup based on a volumetric method which has been schematically shown in Fig. 1. In the beginning, $0.5 \mathrm{~g}$ of adsorbent was poured into the adsorption reactor and then attached to the system. To ensure that there is no leak in the connections, the system was checked with the inert Helium gas flow. In order to degas the system, the valves 6, 7, 8 and 9 were opened and other valves were closed. Then, the system was vacuumed by the vacuum pump for $1.5 \mathrm{~h}$ at $120^{\circ} \mathrm{C}$. After degassing the adsorption system, the temperature was decreased to the experiment temperature. To perform the adsorption test, we opened the valves $1,3,5,6,7$ and 8 while other valves were closed. The pressure drop observed during the process was the result of gas adsorption and some dead volumes 


\section{3 \\ Results and discussion}

134

135

136

137

138

139

140

141

142

143

144

145

146

147

148

149

150

151

152

153

154

155

156

157

158

159

160

161

3

\section{Adsorbent Characterization}

The crystal structures of $\mathrm{NaY}$ zeolite and $\mathrm{NC}$ composite are identified by XRD. As shown in Fig. 2, the XRD pattern of the $\mathrm{NC}$ composite is in perfect agreement with that of $\mathrm{NaY}$ zeolite, indicating that MWCNT incorporation does not destroy the formation of the crystal structure of NaY zeolite. Furthermore, in the composite, the weak peak of CNT at $2 \theta=26^{\circ}$ cannot be observed because of its overlapping with high-intensity peaks of $\mathrm{NaY}$ zeolite. Also, after the incorporation of MWCNTs, peak intensities of the composite are higher, indicating that crystallinity of $\mathrm{NaY}$ zeolite crystals in $\mathrm{NC}$ have improved compared with pure NaY zeolite.

Figure 2

Fig. 3 shows the FT-IR spectra of NaY zeolite and NC composite. In spectrum of NC composite (b), a peak at $2370 \mathrm{~cm}^{-1}$ appears which is associated to hydroxyl groups $(-\mathrm{OH})$ stretch from strongly H-bonded-COOH. ${ }^{37}$ Also the band at $2370 \mathrm{~cm}^{-1}$ can be probably due to $\mathrm{C}=\mathrm{O}$ stretching induced by carboxylation of the carbon nanotubes. ${ }^{38}$ In addition, peaks at $2850-2960 \mathrm{~cm}^{-1}$ indicate the presence of $\mathrm{CH}_{2} \mathrm{CH}_{2} \mathrm{CH}_{2}-\mathrm{NH}_{2}$ groups due to grafting of APTES on MWCNTs surface. These peaks confirm the incorporation of amine modified MWCNTs into the zeolite structure. Furthermore, these spectra show that MWCNTs incorporation did not destroy the zeolite crystal structure.

1

Figure 3

The SEM images of NaY zeolite and NC composite are shown in Fig. 4. As can be seen, after MWCNT incorporation, the crystalline shape of $\mathrm{NaY}$ zeolite in the composite has not changed. The morphologies of $\mathrm{NC}$ composites display that the MWCNTs are well blended with NaY zeolite. It can be seen that the size of NaY zeolite crystals in the $\mathrm{NC}$ composite is smaller than those in the pure NaY zeolite. It is because of the increase of nucleation sites for the formation of NaY zeolite crystals by MWCNTs, leading to the smaller size of NaY zeolite crystals.

Figure 4 
Nitrogen adsorption-desorption isotherms of $\mathrm{NaY}$ zeolite and $\mathrm{NC}$ composite at $77 \mathrm{~K}$ (Fig. 5) are of a typical

type I isotherm, which indicate the microporous feature of these composites. The pore characteristics of adsorbents are listed in Table 1. The results show that when MWCNTs incorporate into NaY zeolite, the surface area and micropore volume of $\mathrm{NC}$ composite improve, due to the formation of extra micropores. Furthermore, the crystal size reduction may also contribute to the increase of the surface area of NC composite. The effect of particle size on the surface area of adsorbents has also been reported by others. ${ }^{39,40}$

\section{Figure 5}

\section{Table 1}

\section{Adsorption Measurement}

The pure $\mathrm{CO}_{2}, \mathrm{CH}_{4}$ and $\mathrm{N}_{2}$ adsorption isotherms on $\mathrm{NaY}$ zeolite and $\mathrm{NC}$ composite at $298 \mathrm{~K}$ were investigated and are shown in Figs. 6 and 7, respectively. Table 2 shows the $\mathrm{CO}_{2}, \mathrm{CH}_{4}$ and $\mathrm{N}_{2}$ adsorption capacities of MWCNTs, NaY zeolite and NC composite at $298 \mathrm{~K}$ and $348 \mathrm{~K}$ and $\mathrm{P}=1 \mathrm{bar}$.

Figure 6

\section{Figure 7}

\section{Table 2}

\section{4}

As expected, adsorption capacity of the three gases enhanced after incorporation of MWCNTs because of the 187 the $\mathrm{NC}$ composite presented a significant increase in the adsorption capacity of $\mathrm{CO}_{2}$ in comparison with $\mathrm{CH}_{4}$ and $\mathrm{N}_{2}$ that could be due to the reaction between the surface amine groups with the $\mathrm{CO}_{2}$ molecules and also because of the high quadrupole moment of $\mathrm{CO}_{2}$ molecules. 
Fig. 8 shows the effect of temperature on $\mathrm{CO}_{2}$ and $\mathrm{N}_{2}$ adsorption capacity on $\mathrm{NC}$ composite. The adsorption

191

192

193

194

195

196

197

198

199

200

201

202

203

204

205

206

207

208

209

210

211

212

213

214 capacity of the both gases decreases with the increasing temperature. The decrease of adsorption capacity with rising temperature implies that adsorption process is exothermic and physisorption.

\section{Figure 8}

Three of the most common adsorption models, the Freundlich, ${ }^{41}$ Langmuir, $^{42}$ and Sips $^{43}$ isotherms, were used to correlate the experimental data of $\mathrm{CO}_{2}$ and $\mathrm{CH}_{4}$ adsorption on $\mathrm{NaY}$ zeolite and $\mathrm{NC}$ composite. The values of model parameters are given in Table 3. Langmuir isotherm corresponds to homogeneous adsorbent surfaces and Freundlich isotherm refers to multilayer adsorption on heterogeneous surfaces. ${ }^{44}$ Langmuir isotherm is represented by the following equation:

$q=q_{m} \frac{b P}{(1+b P)}$

Where $\mathrm{q}$ is the adsorbed capacity $\left(\mathrm{mmol} \mathrm{g}^{-1}\right)$ at equilibrium pressure $\mathrm{P}, \mathrm{q}_{\mathrm{m}}$ and $\mathrm{b}\left(\mathrm{KPa}^{-1}\right)$ are the maximum amount of gas adsorbed $\left(\mathrm{mmol} \mathrm{g}^{-1}\right)$ and the Langmuir constant, respectively.

Freundlich isotherm equation is given as follows:

$q=K_{f} P^{1 / n}$

$$
q=q_{m} \frac{(b P)^{1 / n}}{1+(b P)^{1 / n}}
$$


$215 \quad A R E \%=\frac{100}{N} \sum_{i=1}^{N}\left|\frac{q_{i}^{e x p}-q_{i}^{c a l}}{q_{i}^{\text {exp }}}\right|$

Where ARE (\%) is the average percent deviation, $\mathrm{N}$ is the number of data points available in the adsorption equilibrium isotherms, and $\mathrm{q}^{\text {exp }}$ and $\mathrm{q}^{\mathrm{cal}}$ are the experimental and calculated amounts adsorbed (mmol/g), respectively.

As shown in Table 3, among the three isotherms mentioned above, the Sips isotherm with high correlation coefficients $\left(\mathrm{R}^{2}>0.99\right)$ and an average percent deviation value of less than $2 \%$ provides the best model for adsorbents, and presents the excellent agreement between the model parameters and the experimental data, which indicated the heterogeneous nature of the adsorbents surface.

Table 3

\section{Adsorption Selectivity for gases}

The pure component selectivity for gases was obtained from their adsorption isotherms. By applying Eq 1 and 2 adsorbed at certain temperature and pressure, respectively.

228 $\mathrm{A}_{1 / 2}=\frac{V_{1}}{V_{2}}, T, P$

Fig. 9 shows the adsorption selectivities of $\mathrm{CO}_{2} / \mathrm{CH}_{4}$ on $\mathrm{NaY}$ zeolite, $\mathrm{CNT}$ and $\mathrm{NC}$ composite at different pressures and $298 \mathrm{~K}$. As is clear, the NC composite has higher selectivity than NaY zeolite. Incorporation of CNTs has significantly improved the selectivity of the NC composite compared with NaY zeolite. The formation of the $\mathrm{NC}$ composite by $\mathrm{NaY}$ zeolite crystal growth on CNTs surface significantly increases the micropore volume compared with $\mathrm{NaY}$ zeolite and also creates polarized activated sites or special structures. ${ }^{31,35}$ Consequently, $\mathrm{CO}_{2}$ molecules with the high quadrupole moment have a greater tendency towards $\mathrm{NC}$ composite and therefore, the selectivity of NC composite is higher than NaY zeolite. 

the literature. The selectivity of $\mathrm{NC}$ composite is higher than that of other porous materials (except $\left.\mathrm{Cu}_{3}(\mathrm{BTC})_{2}\right)$ under similar conditions.

\section{Table 4}

Because of high hydrothermal stability and more cost-effectiveness of zeolites compared to other porous materials such as metal organic frameworks, NC composite is a promising candidate for separation and purification of $\mathrm{CO}_{2}$ from $\mathrm{CO}_{2} / \mathrm{CH}_{4}$ mixtures by selective adsorption.

For reduction of greenhouse gas emissions, the removal of $\mathrm{CO}_{2}$ from flue gas in post combustion process is important. The adsorption selectivities of $\mathrm{CO}_{2} / \mathrm{N}_{2}$ on $\mathrm{NaY}$ zeolite and $\mathrm{NC}$ composite at two different temperatures and $\mathrm{P}<5$ bar are shown in Fig. 10. The NC composite has higher selectivity than NaY zeolite. Moreover, selectivities of $\mathrm{CO}_{2} / \mathrm{N}_{2}$ significantly increase at high temperature and low pressure. Since the flue gas pressure, as well as its $\mathrm{CO}_{2}$ concentration is low, therefore, $\mathrm{NC}$ composite is a promising candidate for the capture of $\mathrm{CO}_{2}$ from flue gas. Rising temperature has enhanced selectivity of $\mathrm{CO}_{2} / \mathrm{N}_{2}$ on $\mathrm{NC}$ composite.

\section{Figure 10}

\section{Conclusions}

Zeolite/carbon nanotube composite has been successfully synthesized with hydrothermal method and characterized. The surface area and pore volume of the NC composite and consequently its enhanced adsorption are attributed to increase of nucleation sites after incorporation of MWCNTs into zeolite. Selectivity of NC composite for $\mathrm{CO}_{2} / \mathrm{CH}_{4}$ mixture (2.22) at $298 \mathrm{~K}$ and $\mathrm{p}=1$ bar was higher than that of $\mathrm{NaY}$ zeolite (1.36). Because $\mathrm{CO}_{2}$ molecules have high quadrupole moment while $\mathrm{CH}_{4}$ molecules do not have a quadrupole moment. Selectivities of $\mathrm{NC}$ composite for $\mathrm{CO}_{2} / \mathrm{N}_{2}$ mixture at $\mathrm{p}=1$ bar and $298 \mathrm{~K}$ and $348 \mathrm{~K}$ are 15.2 and 18.9 , respectively, are higher than those of $\mathrm{NaY}$ zeolite (8.8 and 13.9 at $298 \mathrm{~K}$ and $348 \mathrm{~K}$, respectively). Due to the obtained results in this study, NC composite can be a suitable material for the separation and purification of gases in the industrial applications. 
267

268

269

270

271

272

273

274

275

276

277

278

279

280

281

282

283

284

285

286

287

288

289

290

291

292

293

294

295

\section{Acknowledgements}

The authors are grateful to the Research Council of Iran University of Science and Technology (Tehran) and Islamic Azad University, Kerman branch and Iran National Science Foundation (INSF) for the financial support of this project.

\section{References}

(1) Abdeshahian, P.; Dashti, M.; Kalil, M.; Yusoff, W. Biotechnology 2010, 9, 274.

(2) Cavenati, S.; Grande, C. A.; Rodrigues, A. E. Journal of Chemical \& Engineering Data 2004, 49, 1095.

(3) Bucior, B. J.; Chen, D.-L.; Liu, J.; Johnson, J. K. The Journal of Physical Chemistry C 2012, 116, 25904.

(4) Peng, X.; Wang, W.; Xue, R.; Shen, Z. AIChE Journal 2006, 52, 994.

(5) Auta, M.; Hameed, B. H. Chemical Engineering Journal 2014, 253, 350.

(6) Luebke, D.; Myers, C.; Pennline, H. Energy \& Fuels 2006, 20, 1906.

(7) Xiang, Z.; Cao, D.; Lan, J.; Wang, W.; Broom, D. P. Energy \& Environmental Science 2010, $3,1469$.

(8) Salles, F.; Jobic, H.; Devic, T.; Guillerm, V.; Serre, C.; Koza, M. M.; Ferey, G.; Maurin, G. The Journal of Physical Chemistry C 2013, 117, 11275.

(9) Palomino, M.; Corma, A.; Jorda, J. L.; Rey, F.; Valencia, S. Chemical Communications 2012, 48, 215.

(10) Li, P.; Handan Tezel, F. Microporous and Mesoporous Materials 2007, 98, 94.

(11) Xu, X.; Zhao, X.; Sun, L.; Liu, X. Journal of Natural Gas Chemistry 2009, 18, 167.

(12) Montanari, T.; Finocchio, E.; Salvatore, E.; Garuti, G.; Giordano, A.; Pistarino, C.; Busca, G. Energy 2011, 36, 314 .

(13) Xu, X.; Zhao, X.; Sun, L.; Liu, X. Journal of Natural Gas Chemistry 2008, 17, 391.

(14) McEwen, J.; Hayman, J.-D.; Ozgur Yazaydin, A. Chemical Physics 2013, 412, 72.

(15) Li, Y.; Yi, H.; Tang, X.; Li, F.; Yuan, Q. Chemical Engineering Journal 2013, 229, 50.

(16) Dantas, T. L. P.; Luna, F. M. T.; Silva Jr, I. J.; Torres, A. E. B.; de Azevedo, D. C. S.; Rodrigues, A. E.; Moreira, R. F. P. M. Chemical Engineering Journal 2011, 172, 698.

(17) Mulgundmath, V. P.; Tezel, F. H.; Saatcioglu, T.; Golden, T. C. The Canadian Journal of Chemical Engineering 2012, 90, 730 .

(18) Bezerra, D.; Oliveira, R.; Vieira, R.; Cavalcante, C., Jr.; Azevedo, D. S. Adsorption 2011, $17,235$.

(19) Chatti, R.; Bansiwal, A. K.; Thote, J. A.; Kumar, V.; Jadhav, P.; Lokhande, S. K.; Biniwale, R. B.; Labhsetwar, N. K.; Rayalu, S. S. Microporous and Mesoporous Materials 2009, 121, 84. 
296

297

298

299

300

301

302

303

304

305

306

307

308

309

310

311

312

313

314

315

316

317

318

319

320

321

322

323

324

(20) Chen, X.; Guo, J.; Fu, Z.; He, H.; Long, Y. Journal of Porous Materials 2013, 20, 1271.

(21) Lopes, F. V. S.; Grande, C. A.; Ribeiro, A. M.; Vilar, V. J. P.; Loureiro, J. M.; Rodrigues, A. E. Journal of Chemical \& Engineering Data 2010, 55, 184.

(22) Zhao, Z.; Cui, X.; Ma, J.; Li, R. International Journal of Greenhouse Gas Control 2007, 1, 355.

(23) Katsuki, H.; Furuta, S.; Watari, T.; Komarneni, S. Microporous and Mesoporous Materials 2005, 86, 145.

(24) Ma, J.; Sun, H.; Su, S.; Cheng, W.; Li, R. Journal of Porous Materials 2008, 15, 289.

(25) Ma, J.; Tan, J.; Du, X.; Li, R. Microporous and Mesoporous Materials 2010, 132, 458.

(26) Okada, K.; Shimizu, Y.-I.; Kameshima, Y.; Nakajima, A. Journal of Porous Materials 2005, 12, 281.

(27) Lee, J.-S.; Kim, J.-H.; Kim, J.-T.; Suh, J.-K.; Lee, J.-M.; Lee, C.-H. Journal of Chemical \& Engineering Data 2002, 47, 1237.

(28) Kim, J.-H.; Lee, C.-H.; Kim, W.-S.; Lee, J.-S.; Kim, J.-T.; Suh, J.-K.; Lee, J.-M. Journal of Chemical \& Engineering Data 2003, 48, 137.

(29) Adinata, D.; Daud, W.; Aroua, M. Journal of Nanoparticle Research 2007, 9, 555.

(30) Jin, M.; Kurniawan, W.; Hinode, H. Journal of chemical engineering of Japan 2006, 39, 154.

(31) Xiang, Z.; Peng, X.; Cheng, X.; Li, X.; Cao, D. The Journal of Physical Chemistry C 2011, 115, 19864.

(32) Yang, Y.; Ge, L.; Rudolph, V.; Zhu, Z. Dalton Transactions 2014, 43, 7028.

(33) Anbia, M.; Hoseini, V. Chemical Engineering Journal 2012, 191, 326.

(34) Xiang, Z.; Hu, Z.; Cao, D.; Yang, W.; Lu, J.; Han, B.; Wang, W. Angewandte Chemie International Edition 2011, 50, 491.

(35) Dumee, L.; He, L.; Hill, M.; Zhu, B.; Duke, M.; Schutz, J.; She, F.; Wang, H.; Gray, S.; Hodgson, P.; Kong, L. Journal of Materials Chemistry A 2013, 1, 9208.

(36) Pourebrahimi, S.; Kazemeini, M.; Ganji Babakhani, E.; Taheri, A. Microporous and Mesoporous Materials 2015, 218, 144.

(37) Su, F.; Lu, C.; Cnen, W.; Bai, H.; Hwang, J.F. Science of the Total Environment 2009, 407, 3017.

(38) https://gcep.stanford.edu/pdfs/PE5v0XtfTasff29ZflqL4Q/3.6_Wilcox_Public_Version_2012.pdf.

(39) Liu, Q.; Jin, L.-N.; Sun, W.-Y. Chemical Communications 2012, 48, 8814.

(40) Ge, L.; Zhou, W.; Rudolph, V.; Zhu, Z. Journal of Materials Chemistry A 2013, 1, 6350.

(41) Okeola, F.; Odebunmi, E. Advances in Environmental Biology 2010, 329. 
325

326

327

328

329

330

331

332

333

334

335

336

337

338

339

340

341

342

343

344

345

346

347

348

349

350

351

352

353

(42) Garnier, C.; Finqueneisel, G.; Zimny, T.; Pokryszka, Z.; Lafortune, S.; Défossez, P.; Gaucher, E. C. International Journal of Coal Geology 2011, 87, 80.

(43) Foo, K.; Hameed, B. Chemical Engineering Journal 2010, 156, 2.

(44) Rao, G. P. C.; Satyaveni, S.; Ramesh, A.; Seshaiah, K.; Murthy, K.; Choudary, N. Journal of environmental management 2006, 81, 265.

(45) Do, D. D. Adsorption Analysis: Equilibria and Kinetics; World Scientific, 1998; Vol. 2.

(46) Pawar, R. R.; Patel, H. A.; Sethia, G.; Bajaj, H. C. Applied Clay Science 2009, 46, 109.

(47) Xiang, Z. H.; Lan, J. H.; Cao, D. P.; Shao, X. H.; Wang, W. C.; Broom, D. P. The Journal of Physical Chemistry C 2009, 113, 15106.

6

37

38

0

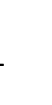

2

4

45

6

48


354 Table captions:

355 Table 1. Structural properties of NaY zeolite and NC composite

356 Table 2. Gas adsorption capacities of NaY zeolite, CNT and NC composite at two temperatures and 1 bar.

357 Table 3. Langmuir, Freundlich, and Sips isotherm parameters for the adsorption of $\mathrm{CO}_{2}$ and $\mathrm{CH}_{4}$ on $\mathrm{NaY}$

358 zeolite and NC composite

359 Table 4. Selectivities of $\mathrm{CO}_{2}$ over $\mathrm{CH}_{4}$ in different porous materials at $298 \mathrm{~K}$ and 1 bar 


\section{$374 \quad$ Figure captions:}

375 Fig. 1 Schematic diagram of volumetric system for adsorption test.

376 Fig. 2 XRD patterns of the NaY zeolite and NC composite.

377 Fig. 3 FT-IR spectra of NaY zeolite and NC composite.

378 Fig. 4 SEM images of NaY zeolite (a,b) and NC composite (c,d).

379 Fig. $5 \mathrm{~N}_{2}$ adsorption - desorption isotherms of $\mathrm{NaY}$ zeolite and NC composite at $77 \mathrm{~K}$.

380 Fig. 6 Adsorption isotherms of $\mathrm{CO}_{2}$ on $\mathrm{NaY}$ zeolite and $\mathrm{NC}$ composite at $298 \mathrm{~K}$.

381 Fig. 7 Adsorption isotherms of $\mathrm{CH}_{4}$ and $\mathrm{N}_{2}$ on $\mathrm{NaY}$ zeolite and $\mathrm{NC}$ composite at $298 \mathrm{~K}$.

382 Fig. 8 Adsorption isotherms of $\mathrm{CO}_{2}$ on $\mathrm{NC}$ composite at $298 \mathrm{~K}$ and $348 \mathrm{~K}$.

383 Fig. 9 Selectivities of $\mathrm{CO}_{2}$ over $\mathrm{CH}_{4}$ in NaY zeolite, CNT and NC composite at $298 \mathrm{~K}$.

384 Fig. 10 Selectivities of $\mathrm{CO}_{2}$ over $\mathrm{N}_{2}$ in $\mathrm{NaY}$ zeolite and $\mathrm{NC}$ composite at $298 \mathrm{~K}$ and $348 \mathrm{~K}$.

385

386 
Table 1 Structural properties of $\mathrm{NaY}$ zeolite and $\mathrm{NC}$ composite

\begin{tabular}{lcc}
\hline Adsorbent & $\mathrm{S}_{\mathrm{BET}}\left(\mathrm{m}^{2} / \mathrm{g}\right)$ & Pore volume $\left(\mathrm{cm}^{3} / \mathrm{g}\right)$ \\
\hline MWCNT & $>200$ & - \\
NaY zeolite & 212 & 0.213 \\
NC & 407.49 & 0.349 \\
\hline
\end{tabular}

396

397

398

399

400

401

402

403

404

405

406

407

408

409

410

411 
412 Table 2 Gas adsorption capacities of NaY zeolite, CNT and NC composite at two temperatures and 1 bar.

\begin{tabular}{|c|c|c|c|c|c|c|}
\hline \multirow{3}{*}{ Adsorbent } & \multicolumn{6}{|c|}{ Gas adsorption capacity (mmol/g) } \\
\hline & \multicolumn{3}{|c|}{$298 \mathrm{~K}$} & \multicolumn{3}{|c|}{$348 \mathrm{~K}$} \\
\hline & $\mathrm{CO}_{2}$ & $\mathrm{CH}_{4}$ & $\mathrm{~N}_{2}$ & $\mathrm{CO}_{2}$ & $\mathrm{CH}_{4}$ & $\mathrm{~N}_{2}$ \\
\hline CNT & 1.19 & 0.63 & 0.17 & 1.02 & - & 0.09 \\
\hline $\mathrm{NaY}$ & 1.9 & 1.4 & 0.21 & 1.67 & - & 0.12 \\
\hline $\mathrm{NC}$ & 4.1 & 1.86 & 0.27 & 3.6 & - & 0.19 \\
\hline
\end{tabular}

413

414

415

416

417

418

419

420

421

422

423

424

425

426

427

428 
429 Table 3 Langmuir, Freundlich, and Sips isotherm parameters for the adsorption of $\mathrm{CO}_{2}$ and $\mathrm{CH}_{4}$ on $\mathrm{NaY}_{\text {zeolite }}$ 430 and NC composite

\begin{tabular}{|c|c|c|c|c|}
\hline \multirow[b]{2}{*}{ Adsorbent } & \multicolumn{2}{|c|}{$\mathrm{CO}_{2}$} & \multicolumn{2}{|c|}{$\mathrm{CH}_{4}$} \\
\hline & $\mathrm{NaY}$ & $\mathrm{NC}$ & $\mathrm{NaY}$ & $\mathrm{NC}$ \\
\hline \multicolumn{5}{|l|}{ Sips } \\
\hline $\mathrm{q}_{\mathrm{m}}(\mathrm{mmol} / \mathrm{g})$ & 1.88 & 4.1 & 1.39 & 1.93 \\
\hline $\mathrm{b}\left(\mathrm{KPa}^{-1}\right)$ & 0.036 & 0.067 & 0.034 & 0.04 \\
\hline $\mathrm{n}$ & 0.262 & 0.397 & 0.352 & 0.426 \\
\hline $\mathrm{R}^{2}$ & 0.995 & 0.999 & 0.996 & 0.998 \\
\hline ARE\% & 1.05 & 0.73 & 0.71 & 1.61 \\
\hline \multicolumn{5}{|l|}{ Langmuir } \\
\hline $\mathrm{q}_{\mathrm{m}}(\mathrm{mmol} / \mathrm{g})$ & 2.07 & 4.24 & 1.50 & 2.14 \\
\hline $\mathrm{b}\left(\mathrm{KPa}^{-1}\right)$ & 0.039 & 0.199 & 0.036 & 0.056 \\
\hline $\mathrm{R}^{2}$ & 0.932 & 0.984 & 0.945 & 0.947 \\
\hline $\mathrm{ARE} \%$ & 4.73 & 2.66 & 4.28 & 4.83 \\
\hline \multicolumn{5}{|l|}{ Freundlich } \\
\hline $\mathrm{K}_{\mathrm{f}}$ & 0.685 & 3.17 & 0.686 & 0.643 \\
\hline $\mathrm{n}$ & 5.7 & 21.39 & 8.08 & 5.22 \\
\hline $\mathrm{R}^{2}$ & 0.830 & 0.964 & 0.874 & 0.854 \\
\hline
\end{tabular}

431

432

433

434

435

436 


Adsorbent $\quad \mathrm{CO}_{2} / \mathrm{CH}_{4}$ selectivity References

\begin{tabular}{lcc}
\hline CNT & 1.88 & This study \\
$\mathrm{NaY}$ & 1.36 & This study \\
$\mathrm{NC}$ & 2.22 & This study \\
MOF-177 & 0.89 & 31 \\
$\mathrm{ZIF-8}$ & 1.32 & 31 \\
$\mathrm{Cu}_{3}(\mathrm{BTC})_{2}$ & 2.28 & 34 \\
$\mathrm{UMCM}-1$ & 1.82 & 47 \\
\hline
\end{tabular}

439

440

441

442

443

444

445

446

447

448

449

450

19

https://mc06.manuscriptcentral.com/cjc-pubs 
Fig. 1 Schematic diagram of volumetric system for adsorption test.

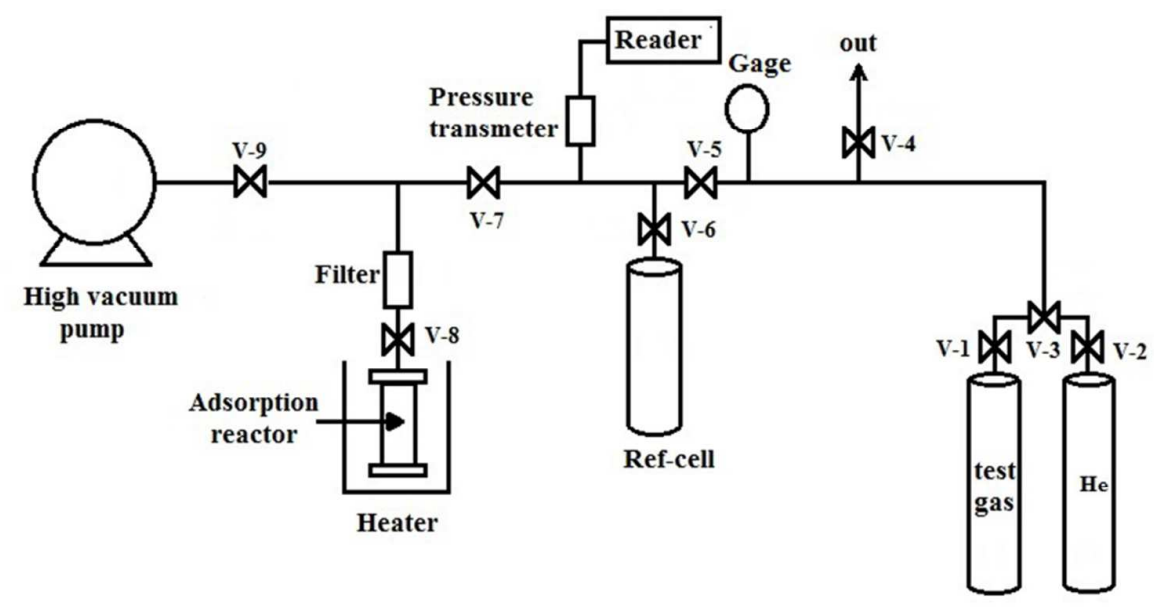

452

453

454

455

456

457

458

459

460

461

462

463

464

465

466

467

468 
Fig. 2 XRD patterns of the NaY zeolite and NC composite.

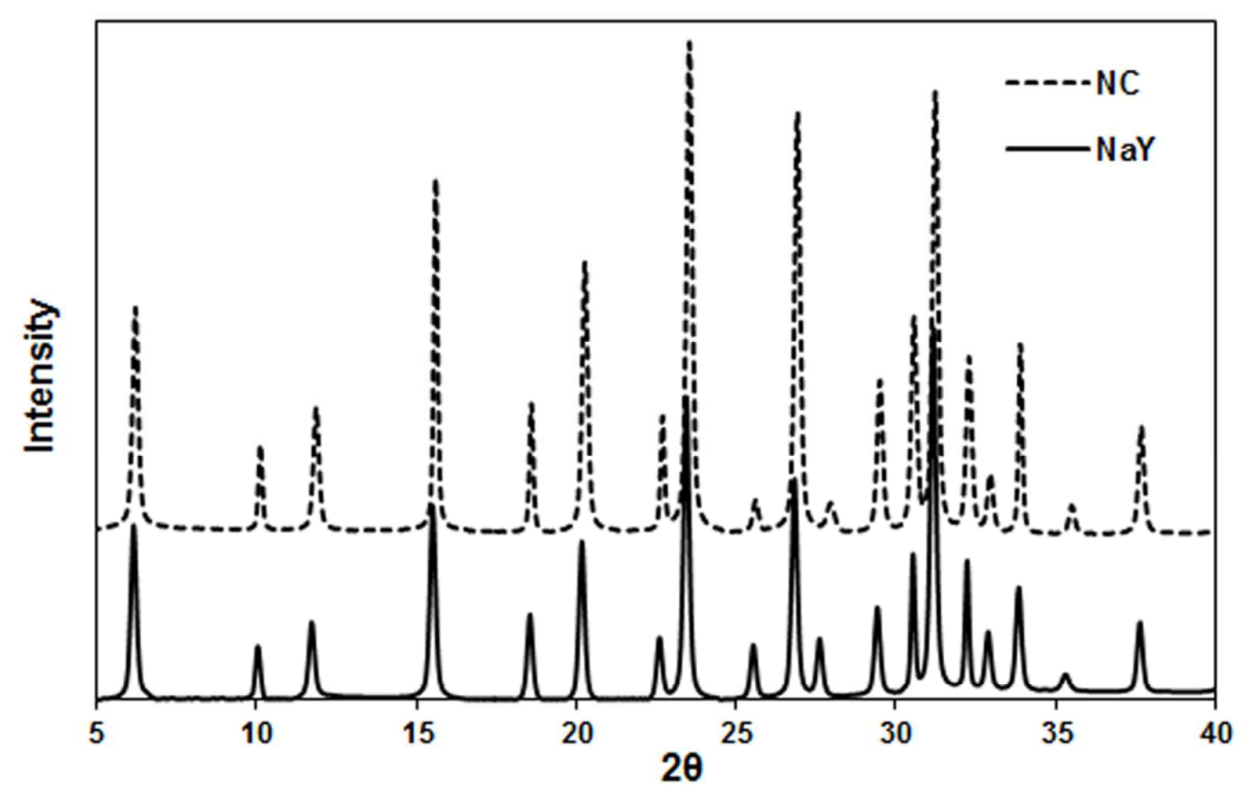

470

471

472

473

474

475

476

477

478

479

480

481

482

483

484 
Fig. 3 FT-IR spectra of NaY zeolite and NC composite.

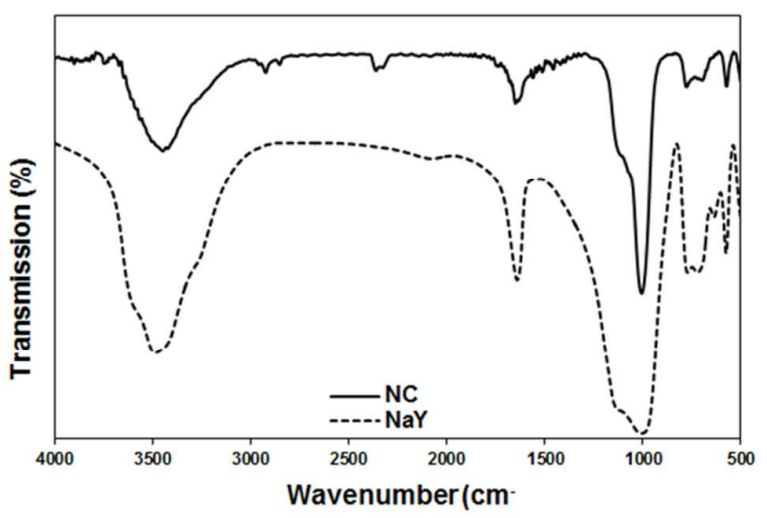

486

487

488

489

490

491

492

493

494

495

496

497

498

499

500

501

502

503 

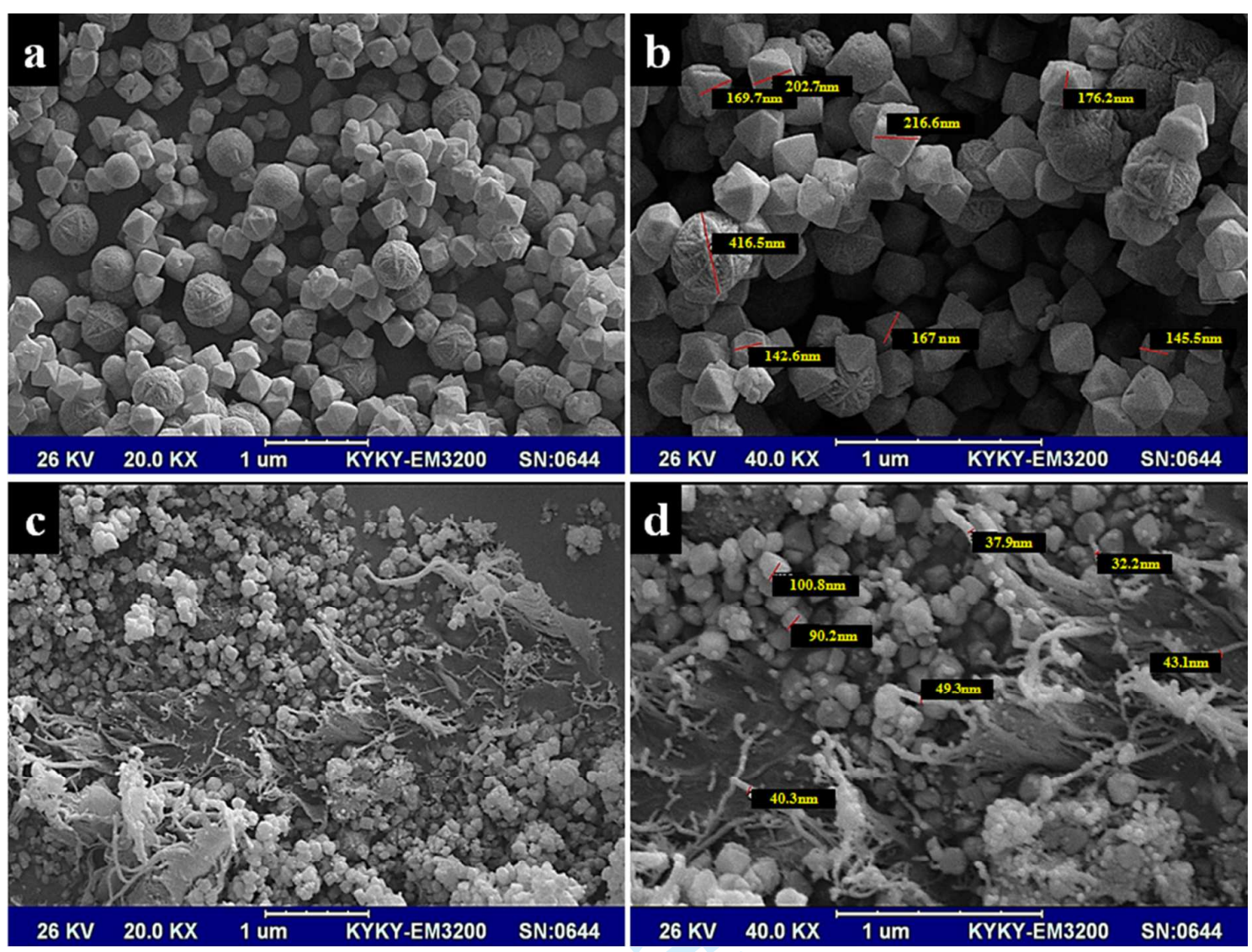

506

507

508

509

510

511

512

513

514

515

516 
Fig. $5 \mathrm{~N}_{2}$ adsorption-desorption isotherms of $\mathrm{NaY}$ zeolite and $\mathrm{NC}$ composite at $77 \mathrm{~K}$.

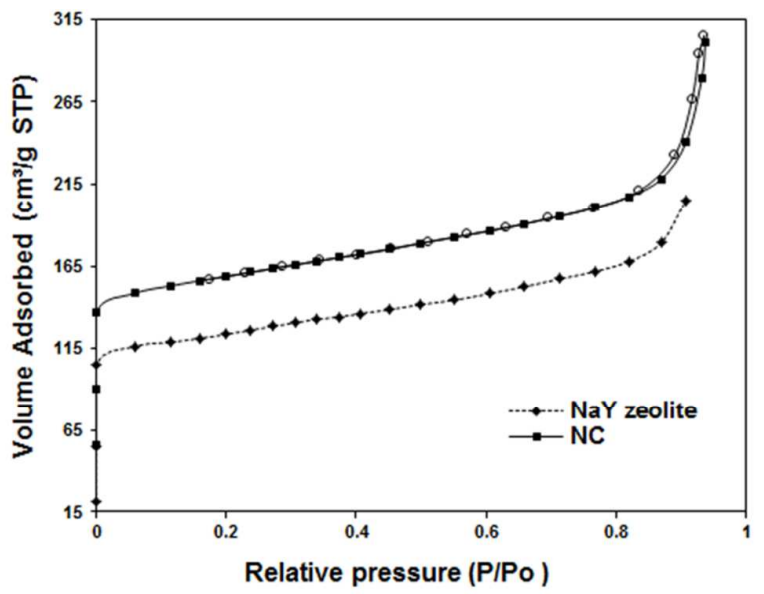

518

519

520

521

522

523

524

525

526

527

528

529

530

531

532

533

534 


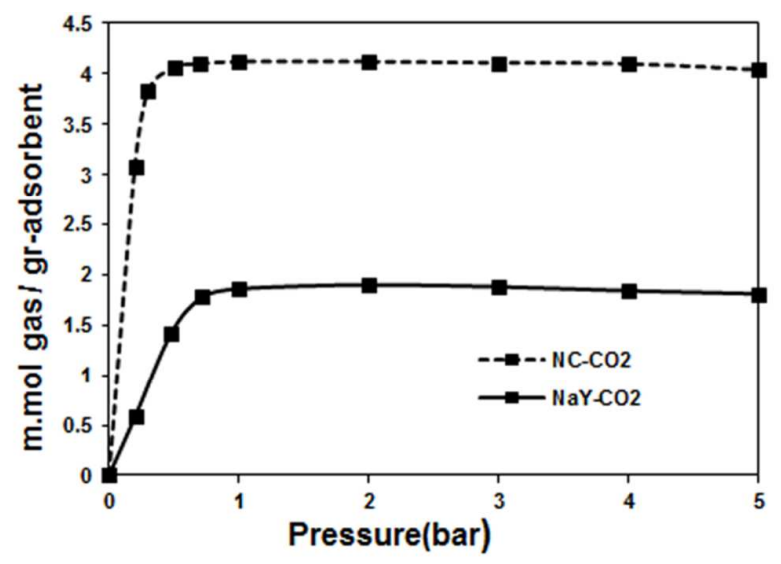


Fig. 7 Adsorption isotherms of $\mathrm{CH}_{4}$ and $\mathrm{N}_{2}$ on $\mathrm{NaY}$ zeolite and $\mathrm{NC}$ composite at $298 \mathrm{~K}$.

555

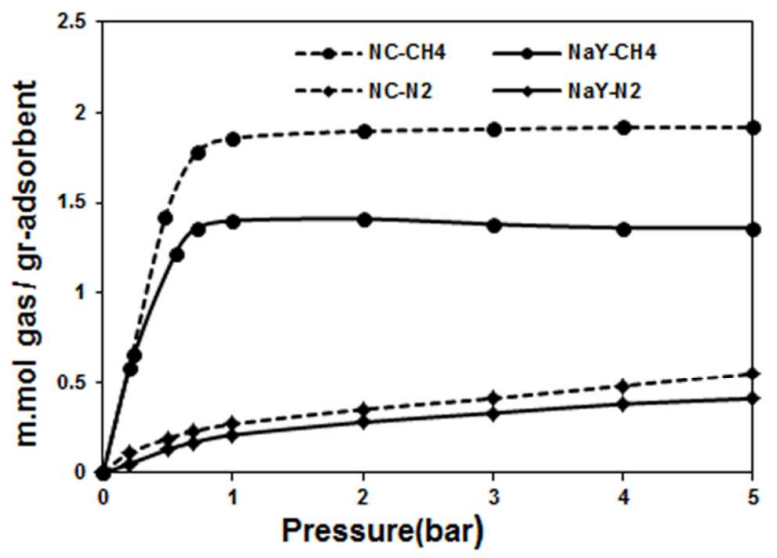

556

557

558

559

560

561

562

563

564

565

566

567

568

569

570

571

572 
Fig. 8 Adsorption isotherms of $\mathrm{CO}_{2}$ on $\mathrm{NC}$ composite at $298 \mathrm{~K}$ and $348 \mathrm{~K}$.

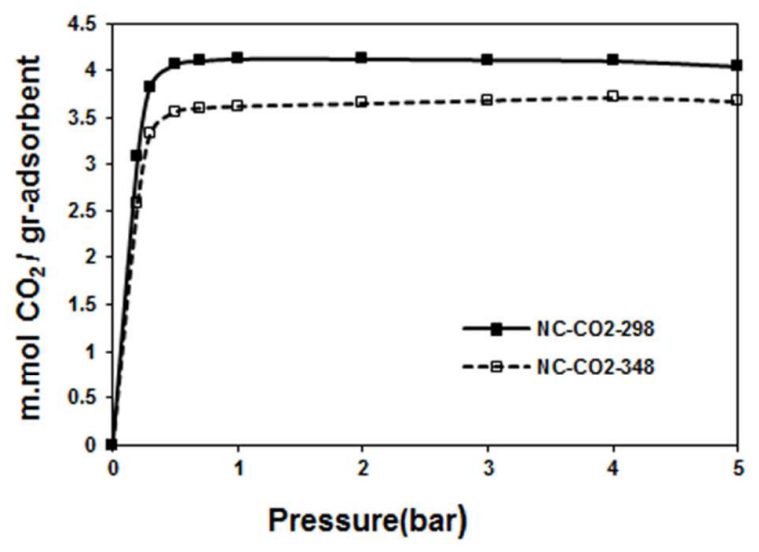

575

576

577

578

579

580

581

582

583

584

585

586

587

588

589

590

591 
Fig. 9 Selectivities of $\mathrm{CO}_{2}$ over $\mathrm{CH}_{4}$ in $\mathrm{NaY}$ zeolite, $\mathrm{CNT}$ and $\mathrm{NC}$ composite at $298 \mathrm{~K}$.

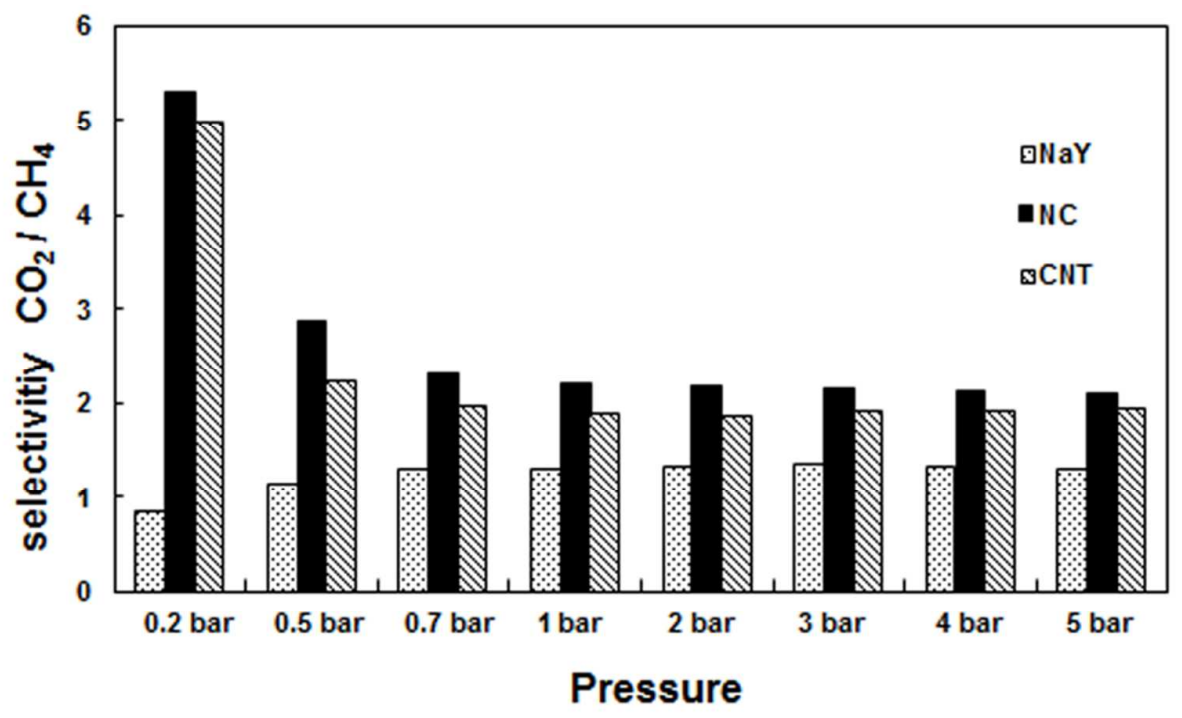

593

594

595

596

597

598

599

600

601

602

603

604

605

606

607

608 
Fig. 10 Selectivities of $\mathrm{CO}_{2}$ over $\mathrm{N}_{2}$ in $\mathrm{NaY}$ zeolite and $\mathrm{NC}$ composite at $298 \mathrm{~K}$ and $348 \mathrm{~K}$.

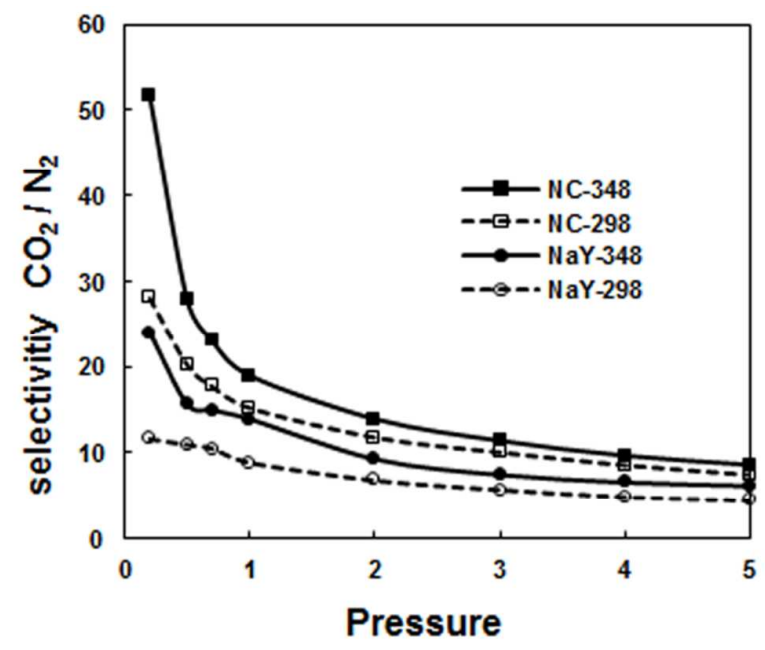

611

612

613

614

615

616

617

618

619

620

621

622 
Graphical Abstract

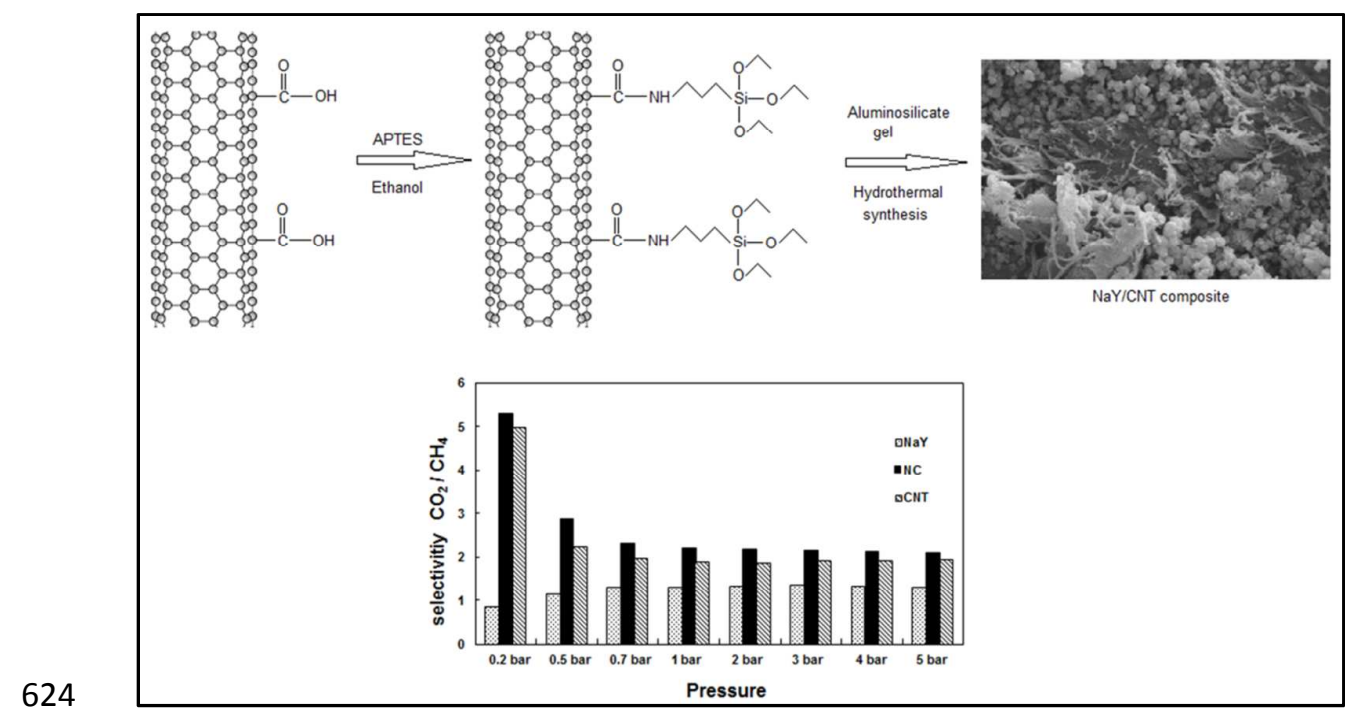

625

626

627

628

629

630

631

632

633

634

635

636

637 


\section{Highlights}

639 - NaY/CNT composite was synthesized by the hydrothermal method and characterized.

640 - The incorporation of MWCNT improved the porosity of the zeolite.

641 - $\mathrm{CO}_{2}, \mathrm{CH}_{4}$ and $\mathrm{N}_{2}$ adsorption capacity enhanced after incorporation of MWCNTs into the zeolite.

642 - $\mathrm{NC}$ composite showed improved selectivity for $\mathrm{CO}_{2} / \mathrm{CH}_{4}$ and $\mathrm{CO}_{2} / \mathrm{N}_{2}$.

643 - Effect of temperature on $\mathrm{CO}_{2}$ selectivity over $\mathrm{N}_{2}$ was studied.

644

645

646 